This report was prepared as an account of work sponsored by an agency of the United States Government. Neither the United States Government nor any agency thereof, nor any of their employees, makes any warranty, express or implied, or assumes any legal liability or responsibility for the accuracy, completeness, or usefulness of any information, apparatus, product, or process disclosed, or represents that its use would not infringe privately owned rights. Reference herein to any specific commercial product, process, or service by trade name, trademark, manufacturer, or otherwise does not necessarily constitute or imply its endorsement, recommendation, or favoring by the United States Government or any agency thereof. The views and opinions of authors expressed herein do not necessarily state or reflect those of the

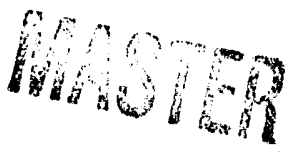
United States Government or any agency thereof. 


\section{VANADIUM-PUMPED TITANIUM X-RAY LASER}

The U.S. Government has rights to this invention pursuant to Contract No. W-7405-ENG-48 between the U.S. Department of Energy and the University of California, for the operation of Lawrence Livermore National Laboratory.

\section{BACKGROUND OF THE INVENTION}

The invention described herein relates generally

to $x$-ray lasers and more particularly to resonantly photo-pumped $x$-ray lasers.

The first operational laboratory $x$-ray laser, which used collisional excitation as the pumping mechanism, was taught by Campbell and Rosen in U.S. Patent 4,827,47y issued May 2, 1989. Moreover, this x-ray laser is also described by Rosen et al. in Physical Review Letters 54, 106 (1985), with a discussion of the experimental demonstration of the laser provided by Matthews 6 t al in Physical Review Letters 54, 110 (1985). 
This seminal work was also reported in Physics Today, March 1985, at pages 17 to 19. Additionally, a recent review of soft $x-r a y$ lasers is provided by Matthews and Rosen in Scientific American, December 1988, at pages 86 to 91 .

The following are representative of the

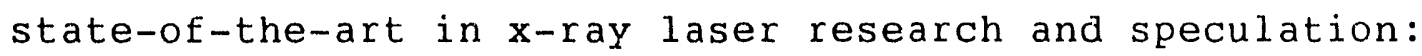
Cochran et al, in U.S. Patent 4,803,687 issued February 7, 1989, describe a sodium-neon laser target wherein Ne IX (He-like $\mathrm{Ne}$ ) is resonantly photo-pumped by $\mathrm{Na} \mathrm{X}$ (He-like $\mathrm{Na}$ ). A carbon thermal buffer layer is required between the sodium and neon layers.

Hagelstein, in U.S. Patent $4,660,203$ issued April 21, 1987, describes x-ray lasers wherein various

15 multiply ionized species are used to pump high energy transitions in helium-like or hydrogen-like $\mathrm{N}, \mathrm{O}, \mathrm{F}, \mathrm{C}$ or rare gases. For example, F-like $\mathrm{T} i$ is indicated as a pump material at $24.907 \mathrm{~A}$ to drive a He-like $\mathrm{N}$ laser. The lasant material is located within a hollow container

20 fabricated from parylene, or a material substantially transparent to radiation in the wavelength range from 60 to 300 Angstroms, and is multiply-ionized and undergoes at least one super-radiant laser transition.

Silfvast, in U.S. Patent 4,592,064 issued May 27, 25 1986, discloses a scheme that permits high gain at visible 
and UV wavelengths in species such as Cd and $\mathrm{Zn}$. A population inversion is established by producing a plasma that generates $x$-ray pulses in the 150 to 650 Angstrom ( $\AA$ ) wavelength range.

Elton, in U.S. Patent 4,592,056 issued May 27, 1986, describes $x$-ray lasing systems wherein a neon-like sulfur plasma is used to pump a lithium-like neon plasma, and wherein a lithium-like silicon plasma is used to pump a lithium-like magnesium plasma.

Harris, in U.S. Patent 4,380,072 issued April 12, 1983, describes a method of exciting atoms to a storage level, then irradiating the excited atoms and thereby raising them to a higher level, whereupon the atoms lase to a lower level, other than ground, which is

15 simultaneously emptied. This method results in the generation of XUV radiation.

Mani et al, in U.S. Patent $4,229,708$ issued October 21, 1980, describe an x-ray laser wherein lithium-like atoms or ions are stimulated to lase by 20 resonant or non-resonant antistokes Raman processes. The laser functions by directing filtered, black-body radiation in the soft $x$-ray region into a lithium-like vapor.

Jaegle et al, in U.S. Patent 3,826,996 issued 25 July 30 , 1974, describe obtaining a medium having a 
negative absorption coefficient within the ultra-violet and $x$-ray range, by focusing a giant-pulse laser beam on an aluminum target.

Despite tremendous progress in the development of $x$-ray lasers over the last several years, only two pumping mechanisms have been used to create gain and produce laser output. These have been collisional excitation, in the case of Ne-like and $\mathrm{Ni}-\mathrm{like}$ lasers, and recombination, in the case of H-like and Li-like lasers. Proposals have been made of many schemes using the resonant photo-pumping mechanism to drive various $x$-ray lasers; however, the resonant photo-pumping mechanism has not as yet been actually demonstrated in the $x-r a y$, or even the soft $x-r a y$, region. The shortest wavelength at which significant gain has been measured using resonant photo-pumping is $2163 \AA$ in beryllium-like carbon pumped by a manganese plasma, in work reported by Qi and Krishnan, Phys. Rev. Lett. 59, 2051 (1987).

Nilsen, in U.S. Patent 4,977,572 issued

20 December 11, 1990, describes a resonantly photo-pumped $x$-ray laser that enhances the gain of several laser lines that also lase because of collisional excitations and recombination processes. An aluminum and erbium foil combination is driven by two beams of intense line focused 25 optical laser radiation. Ground state Ni-like Er ions are 
resonantly photo-pumped by line emission from $\mathrm{H}-1$ ike $\mathrm{Al}$

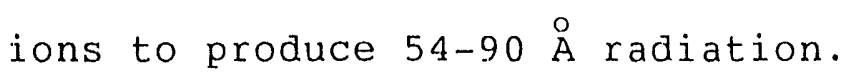

Nilsen in U.S. Patent Application Serial No. 07/420,433, Eiled October 12, 1989, describes a resonantly photo-pumped $x$-ray laser in the 23-44 Angstrom range. A silicon and dysprosium foil combination is driven by two beams of intense line focused optical radiation. Ground state nickel-like dysprosium ions are resonantly photo-pumped by line emission from hydrogen-like silicon ions.

\section{SUMMARY OF THE INVENTION}

It is, therefore, an object of the invention to provide a resonantly photo-pumped $\mathrm{x}$-ray laser.

Additional objects, advantages and novel features of the invention will be set forth in part in the description which follows, and in part will become apparent to those skilled in the art upon examination of the following or may be learned by practice of the invention. The objects and advantages of the invention may be realized and attained by means of the

20 instrumentalities and combinations particularly pointed out in the appended claims.

To achieve the foregoing and other objects and in accordance with the purposes of the present invention, as 
embodied and broadly described herein, a resonantly photo-pumped $x$-ray laser is disclosed in which means are provided for producing a quantity of neon-like titanium ions in the ground state, together with means for resonantly photo-pumping two $2 \mathrm{p} \rightarrow 4 \mathrm{~d}$ transitions in these ions to a pair of 4 d levels, which decay directly to the $3 \mathrm{p}$ upper laser states of the laser, which lases on several $3 p \rightarrow 3 s$ transitions with wavelengths in the 280-510 range. The resonant photo-pumping is accomplished by a means that generates a quantity of fluorine-like vanadium ions in two $3 d$ states, in spatial and temporal proximity to the neon-like titanium ions, with the resonant photo-pumping taking place on two $3 d \rightarrow 2 p$ emission 1 ines from the fluorine-like vanadium ions.

In an embodiment of this invention, the $x$-ray laser comprises a vanadium foil upon which is deposited a titanium film, which together constitute a vanadium and titanium combination. The $V$ foil is generally thicker than the Ti layer. Means are provided for simultaneously 20 illuminating the vanadium and the titanium sides of the combination with beams of line focused, high power optical laser radiation. This driving illumination occurs over adjacent, long and thin and generally rectangular portions of the surfaces of the vanadium foil and titanium film combination. Preferably, the vanadium foil has a 
thickness in the approximate range from 100 to 5,000 Angstroms; and the titanium film has a thickness in the approximate range from 10 to 2000 Angstroms. Preferably, the two simultaneous, illuminating beams of driving optical laser radiation individually each have wavelengths within the approximate range from 0.25 to 11 microns; and temporal full widths at half maximum amplitude in the approximate range from 10 to 2000 picoseconds. Preferably, the beam that illuminates the vanadium side of the combination has a power density in the approximate range extending from $5 \times 10^{12}$ to $5 \times 10^{13}$ watts $/ \mathrm{cm}^{2}$, and the beam that illuminates the titanium side of the combination has a power density in the approximate range extending from $5 \times 10^{12}$ to $5 \times 10^{13}$ watts $/ \mathrm{cm}^{2}$. Preferably, the adjacent, illuminated, generally rectangular portions of the vanadium and titanium combination, each have a length in the approximate range from 0.4 to 8.0 centimeters, and a width in the approximate range from 50 to 200 microns.

In a particular illustrative embodiment, optical laser pulses of about 0.5 micron wavelength, 600 ps pulsewidth, and intensity of $1 \times 10^{13} \mathrm{w} / \mathrm{cm}^{2}$ (on each side) are used. The $\mathrm{Ti}$ foil has a thickness of $20 \stackrel{\circ}{\text {, and }}$ the $V$ foil thickness is $1000 \AA$. The illumination region 25 has a length of $4.5 \mathrm{~cm}$ and a width of 120 microns. 
The method for providing $x$-ray laser radiation of this invention, comprises the steps of providing a quantity of neon-like titanium ions in the ground state, and resonantly photo-pumping two $2 \mathrm{p} \rightarrow 4 \mathrm{~d}$ transitions of these ions to a pair of 4 d levels, which decay directly to $3 p$ upper laser states which lase on several $3 p \rightarrow 3 s$ transitions. The resonantly photo-pumping step may be accomplished by generating a quantity of $3 \mathrm{~d}$ state Eluorine-like vanadium ions, in spatial and temporal proximity to the neon-like titanium ions, and resonantly photo-pumping on two $3 d \rightarrow 2 p$ emission lines.

In another aspect of this invention, $x$-ray laser radiation may be provided by the single step of simultaneously illuminating the opposite sides of a combination comprised of a vanadium foil, upon which a titanium film has been deposited, with two driving beams of line focused, high power optical laser radiation, over adjacent, long and thin and generally rectangular portions of the vanadium and titanium sides of the combination. The benefits and advantages of the present invention, as embodied and broadly described herein, include, inter alia, the provision of a novel resonantly photo-pumped $x-r a y$ laser. 


\section{BRIEF DESCRIPTION OF THE DRAWINGS}

The accompanying drawings, which are incorporated herein and form a part of the specification, illustrate an embodiment of the invention and, together with the description, serve to explain the principles of the invention. In the drawings:

Figure $I A$ is the energy level diagram of the $x-r a y$ laser of this invention.

Figure $1 B$ is a table of laser transitions, wavelengths and gains for Ne-like $\mathrm{Ti}$.

Figure 2 is a schematic view of an $x$-ray laser in accordance with this invention, shown at an early time in its performance.

Figlire 3 is a schematic view of the $x$-ray laser of Figure 2, shown at a later time in its performance, when vigorously producing $x-r a y$ laser radiation.

\section{DETAILED DESCRIPTION OF THE INVENTION}

The lasing scheme of the novel $x$-ray laser of this invention is shown in the energy level diagram of Figure 1A. The laser uses a combination of titanium $(Z=22)$ and vanadium $(z=23)$. The process comprises resonantly photo-pumping neon-like titanium (Ne-like Ti) ions in the ground state $(\mathrm{J}=0)$ to the $\overline{2 \mathrm{p}}_{3 / 2} 4 \mathrm{~d}_{5 / 2} \quad(\mathrm{~J}=1)$ and $\overline{2 p}_{1 / 2} 4 \mathrm{~d}_{3 / 2}(\mathrm{~J}=1)$ levels. Thjs is accomplished 
using fluorine-like vanadium (F-like V)

$\overline{2 \mathrm{p}}_{3 / 2} \overline{2 \mathrm{p}}_{1 / 2} 3 \mathrm{~d}_{3 / 2}(\mathrm{~J}=5 / 2)$ to $\overline{2 \mathrm{p}}_{3 / 2}(\mathrm{~J}=3 / 2)$ line

emission at $19.366 \AA$, and $\overline{2 p}_{1 / 2} \overline{2 p}_{1 / 2} 3 \mathrm{~d}_{3 / 2}(\mathrm{~J}=3 / 2)$ to $\overline{2 p}_{1 / 2}(J=1 / 2)$ line emission at $19.203 \AA$.

As shown in Figure $1 A$, the basic lasing scheme consists of the $\mathrm{F}-1 \mathrm{ike} \mathrm{V} 3 \mathrm{~d} \rightarrow 2 \mathrm{p}$ lines resonantly photo-pumping electrons in the ground state of the Ne-like $\mathrm{Ti}$ ions to the $\overline{2 \mathrm{p}}_{3 / 2} 4 \mathrm{~d}_{5 / 2}(\mathrm{~J}=1)$ and $\overline{2 p}_{1 / 2} 4 d_{3 / 2}(J=1)$ levels. The bar over the $2 p$ state 10 indicates a hole or vacancy in the closed $L$ shell $\left[1 s^{2} 2 s^{2} 2 p^{6}\right]$ or neon-like core. The notation A represents a $2 p_{3 / 2}$ hole $\left(\widetilde{2 p}_{3 / 2}\right)$ in the neon-like core, while $B$ represents a $2 p_{1 / 2}$ hole $\left(\overline{2 p}_{1 / 2}\right)$. The value of the total angular momentum $J$ is given next to each level.

15 The $\overline{2 \mathrm{p}}_{1 / 2} 4 \mathrm{~d}_{3 / 2}(\mathrm{~J}=1)$ level decays preferentially to the $\overline{2 p}_{1 / 2} 3 \mathrm{p}_{1 / 2}(\mathrm{~J}=0)$ and $\overline{2 \mathrm{p}}_{1 / 2} 3 \mathrm{p}_{1 / 2}(\mathrm{~J}=1)$ levels, which are the upper laser states. These upper laser levels lase to the $\overline{2 p}_{1 / 2} \mathrm{~s}_{1 / 2}(\mathrm{~J}=1)$ level, which is the lower laser level. The lower laser level decays back 20 to the Ne-like ground state. The $\overline{2 p}_{3 / 2} 4 \mathrm{~d}_{5 / 2} \quad(\mathrm{~J}=1)$ level decays strongly to the ${\overline{2 p_{3}}}_{3 / 2} 3 \mathrm{p}_{3 / 2}(\mathrm{~J}=0)$ and $\overline{2 p}_{3 / 2} 3 p_{3 / 2}(J=1)$ levels. These two levels lase to the $\overline{2 p}_{3 / 2} 3 s_{1 / 2}(\mathrm{~J}=1)$ level. Other levels are also fed by the decay of the 4 d levels and result in additional laser 25 lines (not shown). All the laser transitions, along with 
the wavelengths and gains of the laser lines, are given in Figure 1B.

Even in the absence of any fluorine-like vanadium pumping radiation, it is expected that some laser transition lines would be present in a neon-like titanium plasma, because of collisional excitation and recombination processes. However, the presence of fluorine-like vanadium pumping radiation is expected to significantly enhance the gain of each of the lines. On the other hand, some laser lines are only expected to exhibit gain when fluorine-like vanadium is present to photo-pump the neon-like titanium.

Figures 2 and 3 offer a schematic view of an $x-r a y$ laser 10 , in accordance with this invention. $x$-ray laser 10 is the presently preferred embodiment of this invention, aithough it is believed that many different and highly beneficial embodiments of this invention may be realized in various situations and applications. X-ray laser 10 is shown at an early time in its performance in 20 Figure 2, and at a later time, when vigorously producing $x$-ray laser radiation, in Figure 3. A consistent set of reference numerals is used in Figures 2 and 3 . Since laser 10 is an $x$-ray laser, it utilizes no mirrors; therefore, amplification takes place on only a single pass through the system. In this respect, $x$-ray 1 aser 10 is typical of several previously known $x$-ray lasers. 
$\mathrm{X}$-ray laser 10 is comprised of a vanadium foil 12, that is flat and preferably has a thickness in the approximate range from 100 to 5000 Angstroms. A titanium film 14, flat and having a preferred thickness in the approximate range from 10 to 2000 Angstroms, is deposited upon, or attached to, vanadium foil 12, by techniques that are very well-known in the prior art. In some embodiments of this invention, vanadium foil 12 and titanium film 14 may each be attached to and supported by a very thin separating plastic layer, not shown, comprised of, Eor example, mylar or parylene. This plastic layer may provide hydrodynamic isolation between the two foils. Vanadium foil 12 and titanium film 14 together provide a combination 16. The vanadium side of combination 16 is illuminated by a beam of line focused, high power optical laser radiation 18, while, simultaneously, the titanium side of combination 16 is jlluminated by a beam of line focused, high power optical laser radiation 20 , as shown. As schematically indicated, optical laser beams 18 and 20 are line focused by a pair of cylindrical lenses 22 and 24, respectively: by techniques that are very well known in the laser-related arts. Freferably, the two simultaneous beams of optical laser radiation 18 and 20 individually each have a wavelength or wavelengths in the approximate range from .25 to 11 microns, and a temporal 
full width at half maximum amplitude in the approximate range from 10 to 2000 picoseconds. Optical laser beam 18, that illuminates vanadium foil 12, preferably has a power density in the approximate range extending from $5 \times 10^{12}$ to $5 \times 10^{13}$ watts $/ \mathrm{cm}^{2}$, and optical laser beam 20 , that illuminates titanium film 14, preferably has a power density in the approximate range extending from $5 \times 10^{12}$ to $5 \times 10^{13}$ watts $/ \mathrm{cm}^{2}$. Optical laser pulses having characteristics within these ranges are routinely prov ded by the Lawrence Livermore National Laboratory, located at Livermore, California. Optical laser beams 18 and 20 each illuminate an adjacent, long and thin and generally rectangular area on an opposite side of the vanadium and titanium combination 16. In particular, an area 26 on the titanium side of combination 16 , is shown in Figure 2 as illuminated by the optical laser beam 20. A similar area, not specifically shown, on the vanadium side of combination 16, is illuminated by optical laser beam 18 . The area, or surface portion, 26 preferably has a length 28 in the approximate range from 0.4 to 8.0 centimeters, and a width 30 in the approximate range from 50 to 200 microns.

In a particular preferred embodiment, the optical pulses have a wavelength of about $0.5 \mathrm{microns}$, and a pulsewidth of $600 \mathrm{ps}$. The Ti fojl has a thickness of $20 \stackrel{\circ}{\AA}$ 
and the $\mathrm{V}$ foil is $1000 \AA$ thick. The illumination region on the foils is $4.5 \mathrm{~cm}$ long and 120 microns wide. The illumination power density on each side of the foil combination is $1 \times 10^{13} \mathrm{~W} / \mathrm{cm}^{2}$.

As shown in Figure 3 , the optical laser beams 18 and 20 energetically convert the portions of the combination 16 upon which they impinge, into a vanadium plasma 32 , and a titanium plasma 34 . The titanium plasma 34 provides very many neon-like titanium ions in the 10 ground state. The vanadium plasma 32 , which is in spatial and temporal proximity to plasma 34 , provides an abundant quantity of fluorine-like vanadium ions in the two $3 d$ states, which vanadium ions emit a large amount of $3 d$ to $2 p$ line emission radiation at $19.366 \AA$ and $19.203 \AA$, which 15 radiation proceeds into plasma 34 and resonantly photo-pumfs many of the neon-like titanium ions that are contained in the plasma 34 , to the desired pair of $4 \mathrm{~d}$ levels. The neon-like titanium ions, in the $4 \mathrm{~d}$ levels, in plasma 34, proceed to provide, in accordance with the mechanisms particularly discussed above in reference to the energy level diagram of Figure $1 A$, a pair of $x-r a y$ laser beams 36 and 38 , schematically indicated, that comprise $\mathrm{x}$-ray laser radiation.

A resonantly photo-pumped laser requires a good resonance between the lasant and a strong pump line which 
are in temporal and spatial proximity. Temporal and spatial proximity mean that the $\mathrm{V}$ and $\mathrm{Ti}$ ions are sufficiently close in space and time so that the pump energy can be absorbed by the lasant. The F-like V $\overline{2 p}_{3 / 2} \overline{2 p}_{1 / 2} 3 \mathrm{~d}_{3 / 2}(\mathrm{~J}=5 / 2) \rightarrow \overline{2 \mathrm{p}}_{3 / 2}(\mathrm{~J}=3 / 2)$ pump line is measured to be at $19.366 \mathrm{~A}$, while the F-like V $\overline{2 \mathrm{p}}_{1 / 2} \overline{2 \mathrm{p}}_{1 / 2} 3 \mathrm{~d}_{3 / 2}(\mathrm{~J}=3 / 2) \rightarrow \overline{2 \mathrm{p}}_{1 / 2}(\mathrm{~J}=1 / 2)$ pump 1 ine is measured to be at $19.203 \AA$. The ground state to the $\overrightarrow{2 p}_{3 / 2} 4 d_{5 / 2}(\mathrm{~J}=1)$ transition in Ne-like $\mathrm{Ti}$ is measured 10 to be at $19.366 \AA$, while the ground state to the $\overline{2 \mathrm{p}}_{1 / 2} 4 \mathrm{~d}_{3 / 2}(\mathrm{~J}=1)$ transition is measured to be at $19.204 \AA$. Thus, good resonance exists.

The $3 d \rightarrow 2 p$ lines of $F-l i k e ~ V$ have sufficient pump strength to pump the Ne-like Ti ions. The table of Figure $1 \mathrm{~B}$ provides the gain of the various laser transitinns for three different values of the pump strength, $0.005,0.010$, and 0.020 photons per mode. Ionization balance can be achieved between the $\mathrm{V}$ and $\mathrm{Ti}$. Ne-like high $\mathrm{Z}$ plasmas have been made routinely in the 20 laboratory. An advantage of the V-pumped $\mathrm{Ti}$ scheme is that the strong $\mathrm{F}-1 \mathrm{ike} \mathrm{V} 3 \mathrm{~d} \rightarrow 2 \mathrm{p}$ lines have sufficient energy to photoionize Na-like Ti to Ne-like Ti, but they do not liave enough energy to photoionize the ground state of Ne-like Ti to F-like Ti. This Eacilitates making a

25 large population of Ne-like Ti without the fear of overionizing. 
Low electron densities near $10^{18} / \mathrm{cc}$ are required for the $\mathrm{Ti}$ lasant region to minimize collisional effects that tend to equilibrate the populations in the $\mathrm{Ti}$ lasing levels. Higiner electron densities, near $10^{20} / \mathrm{cc}$, and electron temperatures, between $100-300 \mathrm{eV}$, are required in the $\mathrm{V}$ plasma to produce the strons pump lines required. Therefore, the Ti will lase in the coronal region of the plasma and be pumped by the adjacent $V$ region which is hotter and denser.

The gains achievable in Ne-like $\mathrm{Ti}$ by resonant photo-pumping were calculated assuming there were two strong F-like lines of equal strength available to pump the two Ne-like $\mathrm{Ti} 2 \mathrm{p} \rightarrow 4 \mathrm{~d}$ transitions, for several values of the pump line strength, $0.005,0.010$, and 0.020 photons per mode, for a $100 \mu$ thick pre-expanded foil of $\mathrm{Ti}$ at an initial ion density of $1.0 \times 10^{19}$ ions/cc, an electron density determined by the ionization of the $\mathrm{Ti}$, and initial ion and electron temperatures of $50 \mathrm{eV}$. The foil was then allowed to expand and cool while a constant pump strength for the F-like V lines was applied to the calculation. After 3.0 ns, the plasma region $300 \mu$ from the surface of the foil is at an electron temperature of $20 \mathrm{eV}, \mathrm{a} \mathrm{Ti}$ ion density of $1.71 \mathrm{x} 10^{1.7} / \mathrm{CC}$, and an electron density of $1.85 \times 10^{18} / \mathrm{cc}$. Under these conditions $14 \%$ of the $\mathrm{Ti}$ ions are in the Ne-like ground 
state. Figure $1 \mathrm{~B}$ shows the grins of the Ne-like Ti laser lines under these plasma conditions. Five of the lines have gains greater than $5 \mathrm{am}^{-1}$ for a pump of 0.01 photons per mode, with the shortest wavelength of the five being at $326.5 \AA$. The gains of several lines are over $10 \mathrm{~cm}^{-1}$ at the higher pump strength. The lasing region is approximately $200 \mu$ thick.

To provide the low $\mathrm{Ti}$ ion densities for optimal pumping, a weak prepulse, e.g., a few nanoseconds before the main optical pulse, can be applied. For example, optical beam 20 (and 18) can include a lower energy prepulse before the higher energy illumination pulse. The prepulse is of sufficient energy to produce a plasma in the ground state, while the higher energy pulse can excite the plasma to the higher states. The prepulse can be applied at the appropriate time so that the $\mathrm{Ti}$ plasma has spread spatially to produce the desired density when the higher excitation pulse is applied.

Instead of thin foils with double sided illumination, thick slab targets with single sided illumination could also be used. Ti and $\mathrm{V}$ plasias in the above-described states will be formed so that resonant photo-pumping occurs. 
It is thus appreciated that in accordance with the invention as herein described and shown in Figures 1 to 3 , a novel resonantly photo-pumped $x$-ray laser is provided. The Ne-like Ti $\mathrm{x}$-ray laser lases on several $3 p \rightarrow 3 s$ lines ranging from 280-510 A based on resonant photo-pumping using radiation from two $3 d \rightarrow 2$ p emission lines in F-like V.

The foreqoing description of a preferred embodiment of the invention has been presented for purposes of illustration and description. It is not intended to be exhaustive or tc limit the invention to the precise form disclosed, and obviously many modifications and variations are possible in light of the above teaching. The embodiment was chosen and described in 15 order to best explain the principles of the invention and its practical application to thereby enable others skilled in the art to best utilize the invention in various embodiments and with various modifications as are suited to the particular use contemplated. It is intended that 20 the scope of the invention be defined by the claims appended hereto. 


\section{VANADIUM-PUMPED TITANIUM X-RAY LASER}

\section{ABSTRACT OF THE DISCLOSURE}

A resonantly photo-pumped $x$-ray laser (10) is formed of a vanadium (12) and titanium (14) foil combination (16) that is driven by two beams $(18,20$ ) of intense line focused $(22,24)$ optical laser radiation. Ground state neon-like titanium ions (34) are resonantly photo-pumped by line emission from fluorine-like vanadium ions (32). 
DOE S- 71,211

\section{COMBINED DECLARATION AND POWER OF ATTORNEY}

As the below named inventor(s), I (we) hereby declare that:

My (Our) residence, post office address and citizenship(s) are as stated below next

to my (our) name(s).

I believe I am the original, first and sole inventor (if only one name is listed below) or an original, first and joint inventor (if plural names are listed below) of the subject matter which is claimed and for which a patent is sought on the invention entitled Vanadium-Pumped Titanium $x$-Ray Laser

the specification of which (check one)

$X X$ is attached hereto $\square$ was filed on as Serial No.

and was amended on (if applicable).

I (We) hereby state that I (we) have reviewed and understand the contents of the aboveidentified specification, including claims, as amended by any amendment referred to above.

I (We) acknowledge the duty to disclose information which is material to the examination of this application in accordance with Title 37, Code of Federal Regulations, $\S 1.56$ (a)

I (We) hereby claim foreign priority benefits under Title 35, United States Code $\S 119$ of any foreign application(s) for patent or inventor's certificate listed below and have also identified below any foreign application for patent or inventor's certificate having a filing date before that of the application on which priority is claimed:

\section{PRIOR FOREIGN APPLICATION(S)}

NONE

Number Country

Filed (Day/Month/Year)

claimed

Number

$\square_{\text {Yes }} \square_{\text {No }}$

I (We) hereby claim the benefit under Title 35, United States Code, $\S 120$ of any United States application(s) listed below and insofar as the subject matter of each of the claims of this application is not disclosed in the prior United States application in the manner provided by the first paragraph of Title 35, United States Code, § 112, I acknowledge the duty to disclose material information as defined in Title 37 , Code of Federal Regulations, $\S 1.56(\mathrm{a})$ which occurred between the filing date of the prior application and the national or PCT international filing date of this application:

NONE

Serial No. Filing Date $\quad$ Status

POWER OF ATTORNEY: As the named inventor(s), I (we) hereby appoint the following attorney(s) and/or agent(s) to prosecute this application and transact all business in the Patent and Trademark Office connected therewith.

\begin{tabular}{|c|c|}
\hline Names and Registration Nos. & Names and Registration Nos. \\
\hline $\begin{array}{ll}\text { Richard E. Constant } & 20,927 \\
\text { William R. Moser } & 24,763 \\
\text { Judson R. Hightower } & 26,603 \\
\text { Richard A. Lambert } & 25,692 \\
\text { Robert J. Marchick } & 27,057\end{array}$ & $\begin{array}{l}\text { Roger S. Gaither } \\
\text { L. E. Carnahan } \\
\text { Henry P. Sartorio }\end{array}$ \\
\hline $\begin{array}{l}\text { Send Correspondence To: } \\
\text { Richard E. Constant } \\
\text { Assistant General Counsel for Patents } \\
\text { Mail Code GC-42 (FORSTL) MS-6F-067 } \\
1000 \text { Independence Avenue S.W. } \\
\text { United States Department of Energy } \\
\text { Washington, D. C. 20585 }\end{array}$ & $\begin{array}{l}\text { Direct Telephone Calls To: } \\
\text { (Name and Telephone Numbers) } \\
\text { L.E. Carnahan } \\
\text { FTS } 532-1430 \\
\text { COM (415) } 422-1430\end{array}$ \\
\hline
\end{tabular}

Page 1 of 2 Pages

U.S.DEPARTMENT OF ENERGY GC F $2050.3(5-83)$ 
I (We) hereby declare that all statements made herein of my (our) own knowledge are true and that all statements made on information and belief are believed to be true; and further that these statements were made with the knowledge that willful false statements and the like so made are punishable by fine or imprisonment, or both, under $\S 1001$ of Title 18 of the United States Code and that such willful false statements may jeopardize the validity of the application or any patent issuing thereon.

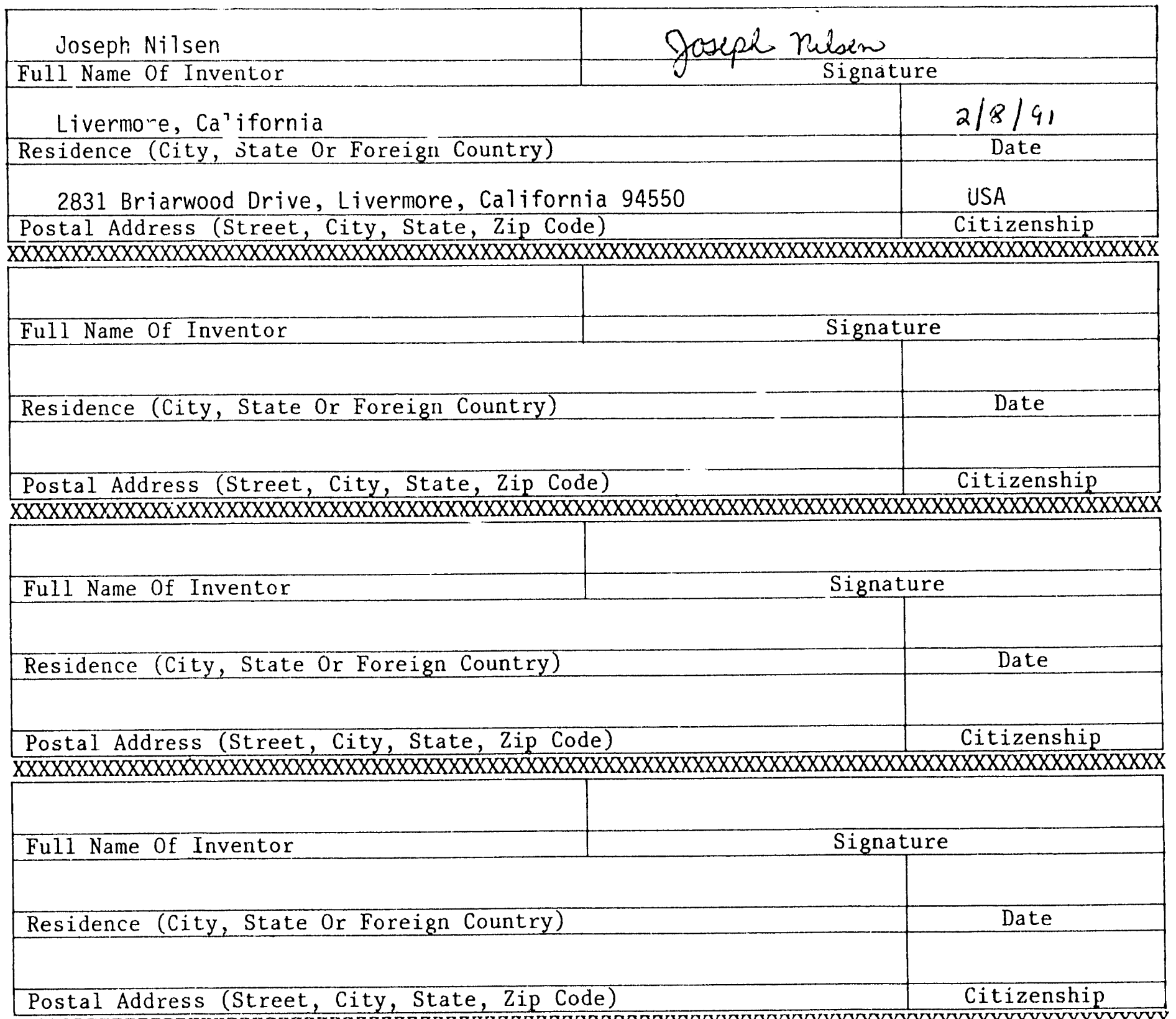

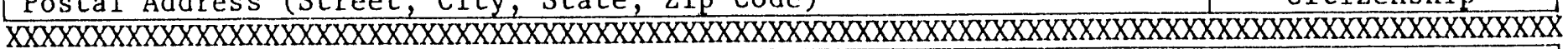

\begin{tabular}{|l|l|l|}
\hline & \multicolumn{2}{|c|}{ Signature } \\
\hline Full Name 0f Inventor & \\
\hline Residence (City, State Or Foreign Country) & Date \\
\hline & \\
\hline Postal Address (Street, City, State, Zip Code) & Citizenship \\
\hline
\end{tabular}




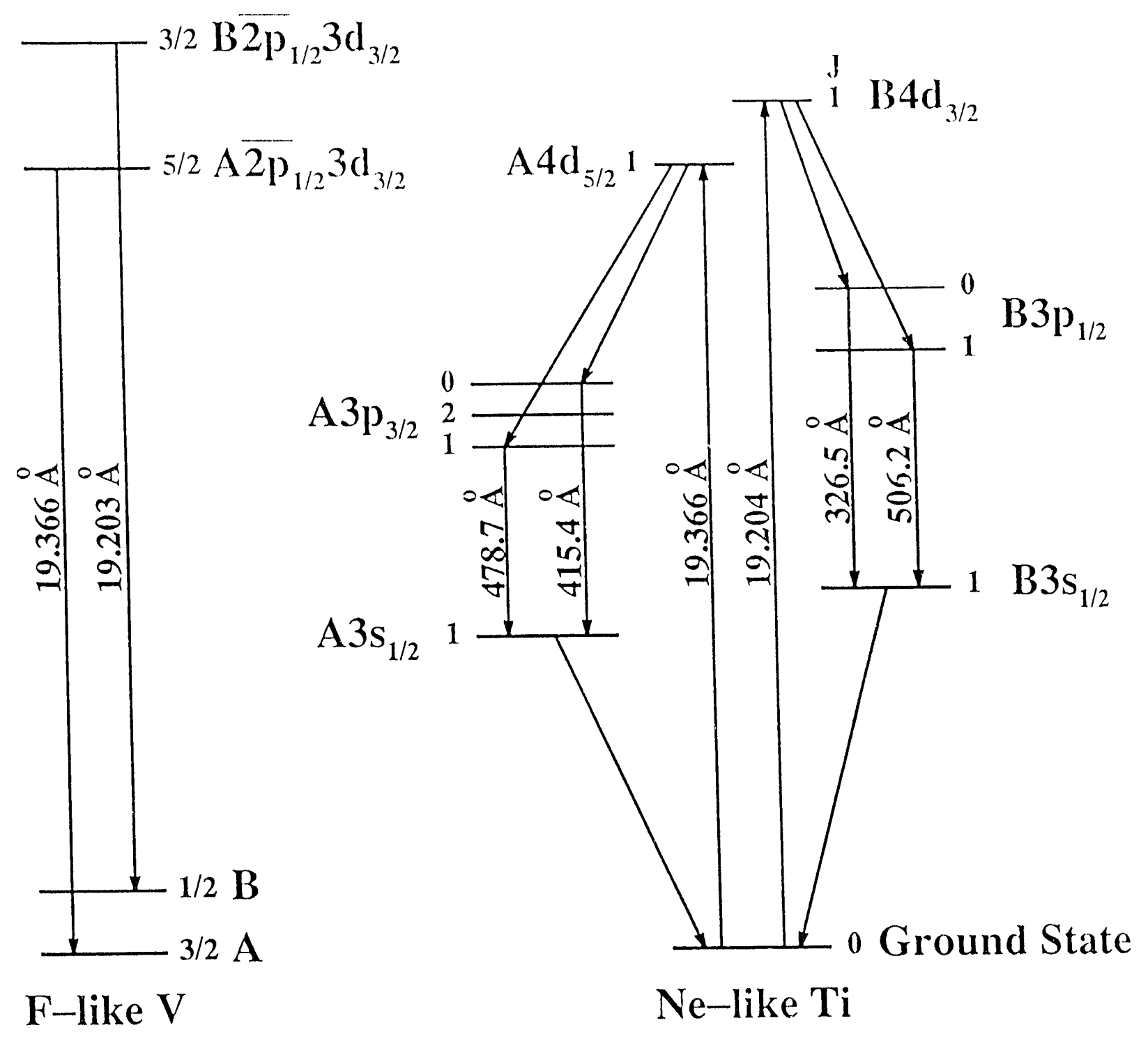

FIG.1A 


\begin{tabular}{|c|c|c|c|c|}
\hline \multirow{2}{*}{ Transition } & \multirow{2}{*}{ Wavelength $(\AA 0$} & \multicolumn{3}{|c|}{$\operatorname{Gain}\left(\mathrm{cm}^{-1}\right)$ for $n_{\lambda}=$} \\
\hline & & 0.005 & 0.010 & 0.020 \\
\hline$\overline{2 p}_{1 / 2} 3 \mathrm{p}_{1 / 2}(\mathrm{~J}=0) \rightarrow \overline{2}_{1 / 2} 3 s_{1 / 2}(\mathrm{~J}=1)$ & 326.5 & 2.90 & 6.81 & 9.91 \\
\hline${\overline{2 p_{1 / 2}}}_{3 p_{3 / 2}}(\mathrm{~J}=2) \rightarrow \overline{2 p}_{1 / 2} 3 \mathrm{~s}_{1 / 2}(\mathrm{~J}=1)$ & 472.1 & & 0.56 & 2.18 \\
\hline${\overline{2 p_{1 / 2}}}_{3 p_{3 / 2}}(\mathrm{~J}=1) \rightarrow \overline{2 p}_{1 / 2} 3 s_{1 / 2}(J=1)$ & 473.2 & 2.10 & 5.45 & 8.78 \\
\hline$\overline{2}_{1 / 2} 3 \mathrm{p}_{1 / 2}(J=1) \rightarrow \overline{2}_{1 / 2} 3 s_{1 / 2}(J=1)$ & 506.2 & 2.90 & 7.44 & 11.88 \\
\hline 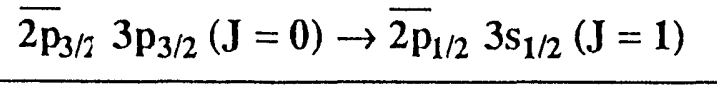 & 508.8 & 1.26 & 2.92 & 4.13 \\
\hline$\overline{2}_{1 / 2} 3 \mathrm{p}_{1 / 2}(\mathrm{~J}=0) \rightarrow{\overline{2 \mathrm{p}_{3 / 2}}} 3 \mathrm{~s}_{1 / 2}(\mathrm{~J}=1)$ & 285.1 & 1.35 & 3.14 & 4.48 \\
\hline 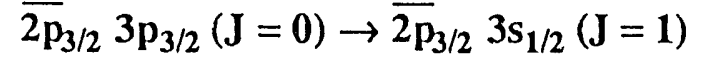 & 415.4 & 2.99 & 6.83 & 9.43 \\
\hline${\overline{2 p_{3 / 2}}}_{3 p_{3 / 2}(J=2) \rightarrow \overline{2 p}_{3 / 2}} 3 s_{1 / 2}(J=1)$ & 459.4 & 0.56 & 2.13 & 4.33 \\
\hline 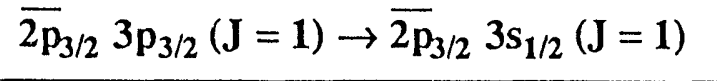 & 478.7 & 3.19 & 8.38 & 13.09 \\
\hline$\overline{2 \mathrm{p}}_{3 / 2} 3 \mathrm{p}_{1 / 2}(\mathrm{~J}=2) \rightarrow \overline{2 \mathrm{p}}_{3 / 2} 3 \mathrm{~s}_{1 / 2}(\mathrm{~J}=1)$ & 507.6 & 1.30 & 4.15 & 7.75 \\
\hline
\end{tabular}




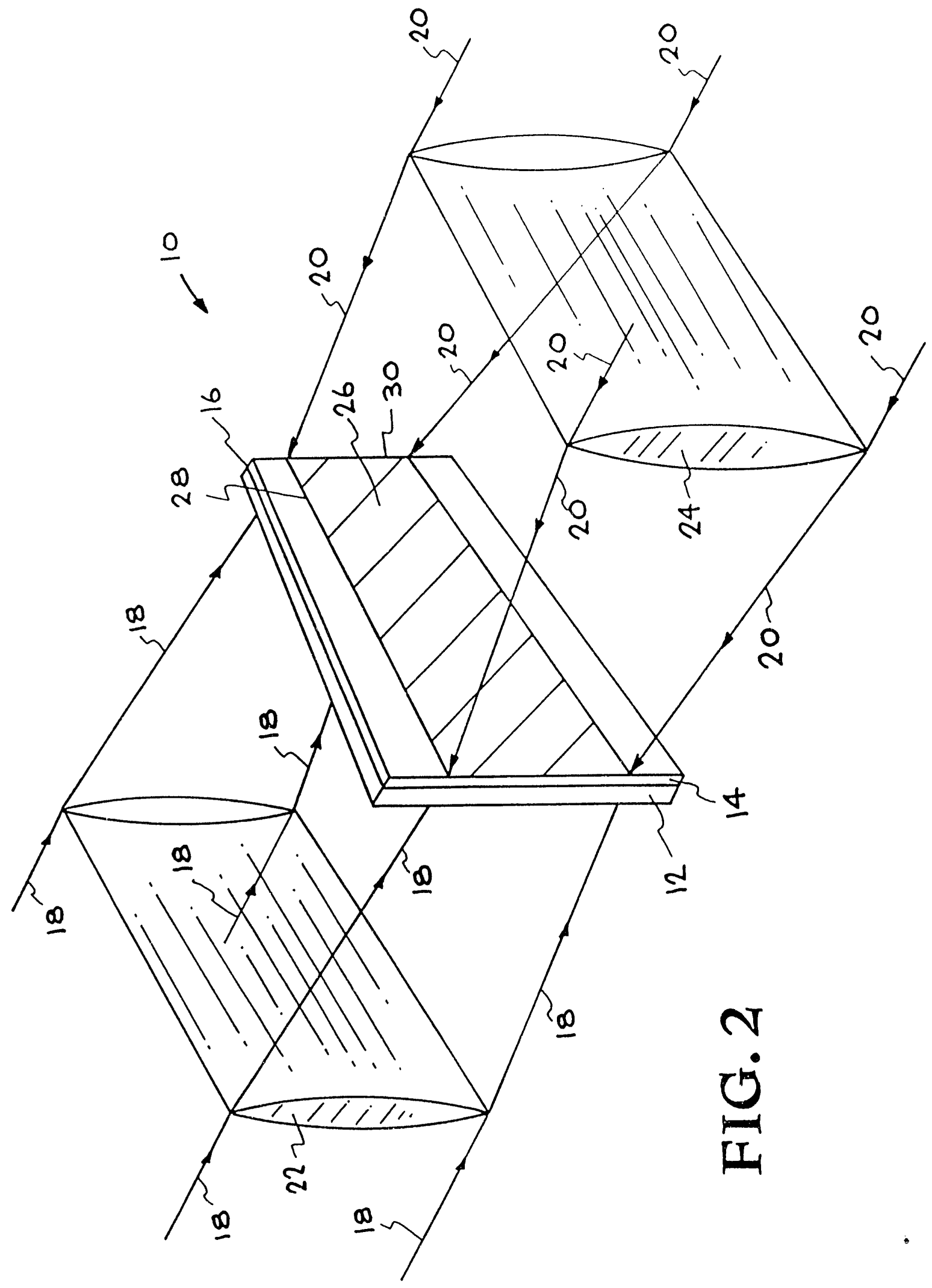




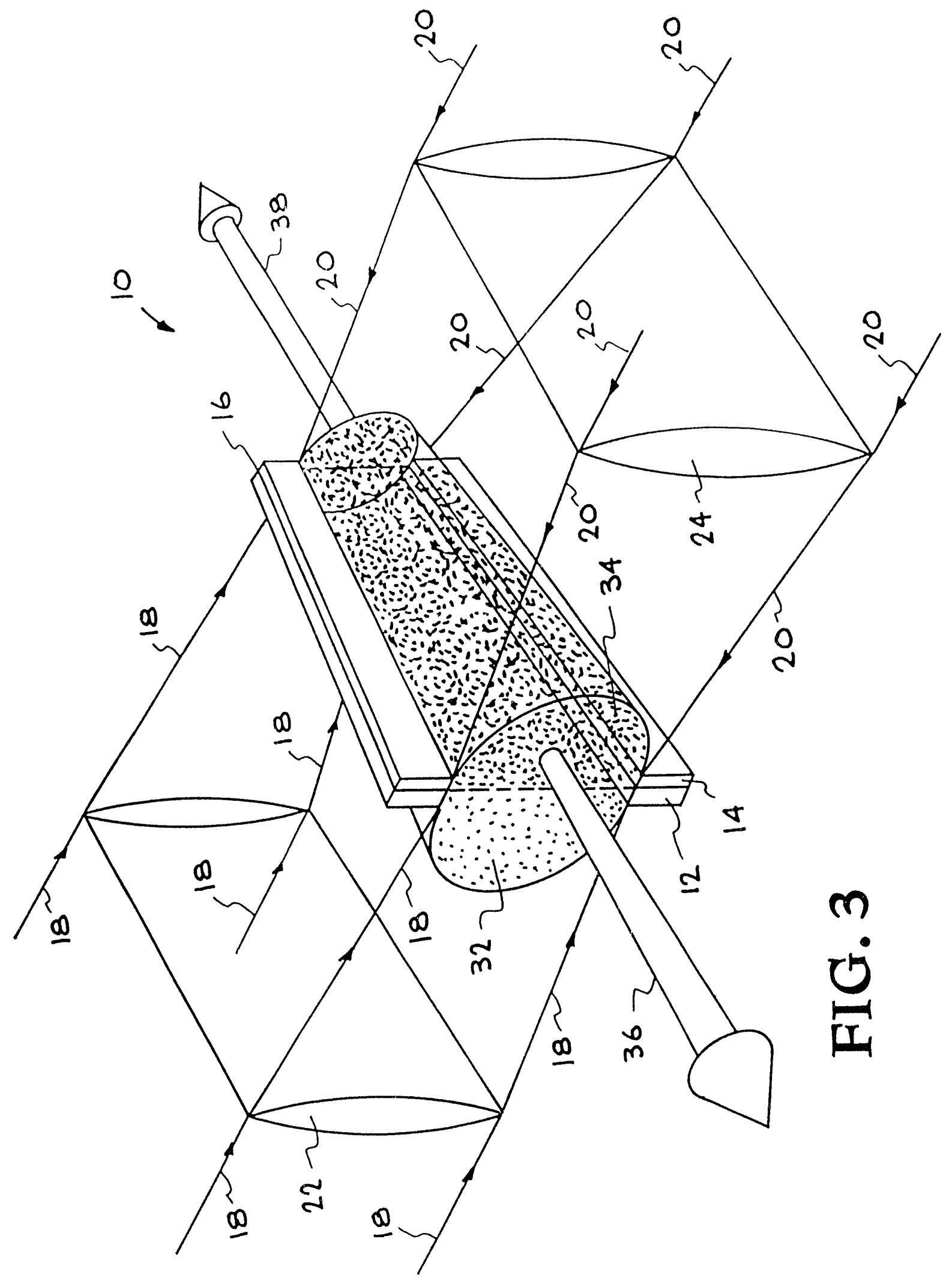


DATE

FILMED

$12 / 17 / 92$ 
